\title{
How a Fully Automated eHealth Program Simulates Three Therapeutic Processes: A Case Study
}

Marianne T. S Holter ${ }^{1}$, Mphil; Ayna Johansen ${ }^{1,2}$, PhD; Håvar Brendryen ${ }^{1}, \mathrm{PhD}$

${ }^{1}$ The Norwegian Centre for Addiction Research, Institute of Clinical Medicine, Faculty of Medicine, University of Oslo, Oslo, Norway

${ }^{2}$ Centre for the Study of Mind in Nature, Faculty of Humanities, University of Oslo, Oslo, Norway

\section{Corresponding Author:}

Marianne T. S Holter, Mphil

The Norwegian Centre for Addiction Research

Institute of Clinical Medicine, Faculty of Medicine

University of Oslo

Postboks 1039 Blindern

Oslo, 0315

Norway

Phone: 4793623061

Fax: 4723368986

Email: m.t.s.holter@medisin.uio.no

\section{Abstract}

Background: eHealth programs may be better understood by breaking down the components of one particular program and discussing its potential for interactivity and tailoring in regard to concepts from face-to-face counseling. In the search for the efficacious elements within eHealth programs, it is important to understand how a program using lapse management may simultaneously support working alliance, internalization of motivation, and behavior maintenance. These processes have been applied to fully automated eHealth programs individually. However, given their significance in face-to-face counseling, it may be important to simulate the processes simultaneously in interactive, tailored programs.

Objective: We propose a theoretical model for how fully automated behavior change eHealth programs may be more effective by simulating a therapist's support of a working alliance, internalization of motivation, and managing lapses.

Methods: We show how the model is derived from theory and its application to Endre, a fully automated smoking cessation program that engages the user in several "counseling sessions" about quitting. A descriptive case study based on tools from the intervention mapping protocol shows how each therapeutic process is simulated.

Results: The program supports the user's working alliance through alliance factors, the nonembodied relational agent Endre and computerized motivational interviewing. Computerized motivational interviewing also supports internalized motivation to quit, whereas a lapse management component responds to lapses. The description operationalizes working alliance, internalization of motivation, and managing lapses, in terms of eHealth support of smoking cessation.

Conclusions: A program may simulate working alliance, internalization of motivation, and lapse management through interactivity and individual tailoring, potentially making fully automated eHealth behavior change programs more effective.

(J Med Internet Res 2016;18(6):e176) doi: 10.2196/jmir.5415

\section{KEYWORDS}

Internet; eHealth; telemedicine; behavior therapy; motivational interviewing; working alliance; intervention mapping; smoking cessation; cell phones; text messaging

\section{Introduction}

"Black boxes," or poorly described programs, have long been a criticism of the eHealth field [1-4], and effective program components across individual interventions are still largely unknown [5]. To address this problem, assumed mechanisms should be adequately described and put in a theoretical context [6]. This would build well-founded hypotheses for active program ingredients. Theoretically founded hypotheses may be especially useful in fully automated programs because automation standardize the therapy that is given. The standardization allows for program elements to be described in 
detail and investigated empirically, free from human variations and with a large degree of reliability. Investigating eHealth programs in light of counseling theories may increase our understanding of how such programs work [6]. In this paper, we will break down the components of an eHealth program and discuss its potential for interactivity and tailoring in terms of common concepts from face-to-face counseling. We hypothesize that simulating the therapeutic processes of supporting a working alliance [7,8], internalized motivation [9], and lapse management [10] simultaneously may be important to optimize behavior change.

According to Riley and colleagues, traditional health behavior change theories are static and linear in nature, and therefore, do not take advantage of the potential involved with interactive eHealth interventions [6]. eHealth interventions are not necessarily static or linear, as they can follow individual users and respond with tailored output to their immediate and previous responses. This enables dynamic adjustment of the intervention delivered, and theories from face-to-face counseling may therefore be more suited to understand eHealth interventions' effective ingredients [6]. In this paper, therefore, we examine Endre, a fully automated program for smoking cessation that uses a fictional "therapist" to conduct tailored "counseling" sessions with the user.

Within eHealth-assisted behavior change, there is a growing interest in the concept of a working alliance [11-22], which is found essential in face-to-face counseling $[7,8]$. The alliance is commonly defined as an emotional bond, as well as agreement on task and goal [7]. It can also be described as therapist processes - such as empathy, warmth, and genuineness, establishing a collaborative framework and offering support and guidance [23]. A strong alliance facilitates client processes that are central to therapy-assisted behavior change, such as expectancies, intentions, motivation, hope, openness, trust, commitment, satisfaction, and a changing view of the self [23]. It may be possible to develop a working alliance to a fully automated program $[12,21,22]$, but so far, there are only a few examples of programs designed to support a working alliance [11,12]. Likewise, motivational interviewing (MI) [24] is considered an effective method to motivate client change in counseling [25]. The effectiveness of MI has been linked to its ability to influence 3 basic psychological needs, including competence, relatedness, and autonomy [26,27]. By supporting these needs, external motivation, a weak form of motivation characterized by performing an activity to gain an external reward or avoid an external punishment, can become internalized. This means the activity is performed because the individual accepts it as an important step toward a personally valued goal [26], improving self-regulation, performance, and persistence $[9,27,28]$. Although MI is often mentioned as one of several methods in eHealth programs [29-33], only 2 report MI as a main method applied extensively [32,33]. Finally, behavior change is difficult, and even when an individual is motivated and the change is going well, he or she still needs to avoid lapses or setbacks in behavior. If a lapse should occur, the individual needs to react constructively to avoid a complete relapse. Teaching people how to prevent a lapse from becoming a relapse (lapse preparation), and helping them manage lapses (lapse management), is thus important when implementing behavior change [10]. Lapse preparation and lapse management have previously been applied to fully automated eHealth programs [31,34-37], but its effect has not been documented. Each therapeutic process has a unique contribution to the user's change process. Supporting internalization of motivation gives the user strength and persistence in upholding the change $[9,27,28]$. Helping the user manage lapses keeps him or her from resuming the old behavior after a setback. Finally, supporting a working alliance makes a positive therapy outcome more likely [7,8] (Figure 1).

No published description exists, as far as we know, of a program supporting all 3 processes simultaneously, as proposed in the theoretical model in Figure 1. The aim of this paper is therefore to illustrate this model through a case study of Endre, a fully automated smoking cessation program, and to forward a hypothesis of these 3 therapeutic processes as important eHealth elements. We use a focused, descriptive analysis to conceptualize the translation from theory to intervention. The analysis is based on a modified intervention mapping protocol [38], which is a framework for designing and planning health promotion interventions through a taxonomy of mapping tools that can be used to code intervention contents. We use the steps that target process theory, methods, and design integration (steps 2-4) to focus on the 3 therapeutic processes that constitute the working hypothesis of Endre. This paper therefore also exemplifies the use of intervention mapping as an approach ideally suited to investigate potentially important elements in the "black box" of eHealth programs. 
Figure 1. Different therapeutic processes affect behavior change differently.

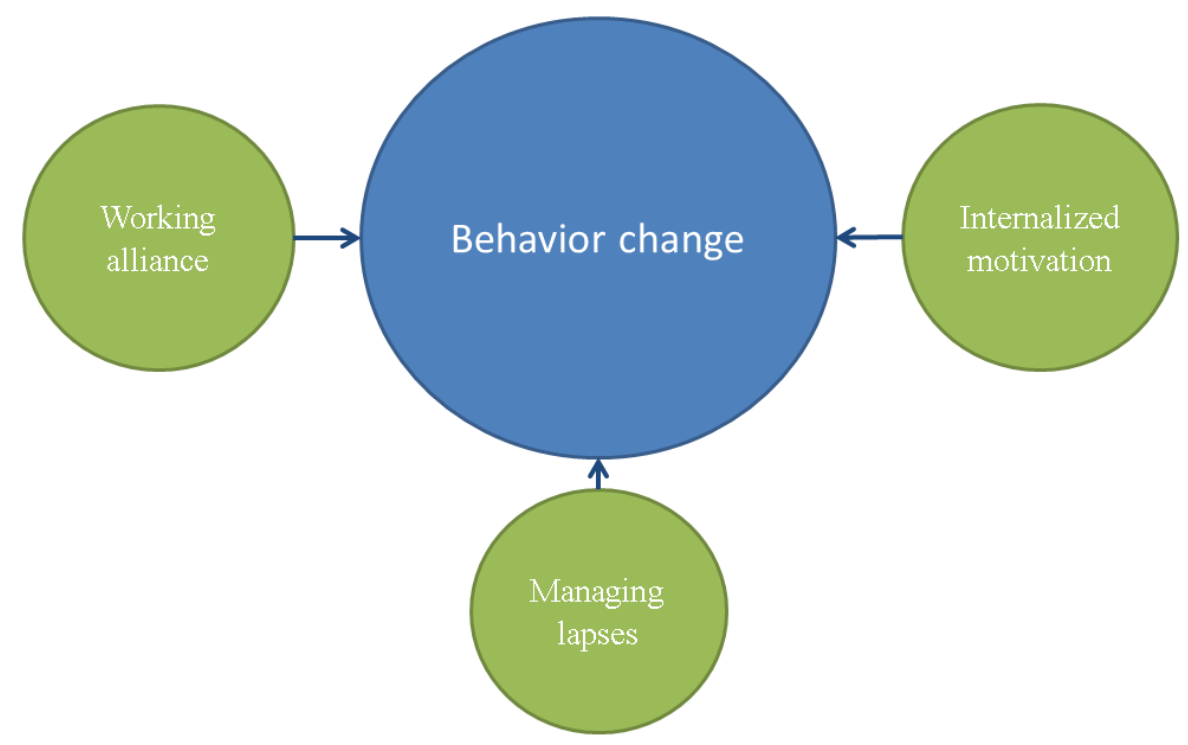

\section{Methods}

\section{The Case: Endre}

Endre is a fully automated eHealth program for smoking cessation that has evolved from the third author's experience with the smoking cessation program Happy Ending [34]. Endre has some of the same basic structures as Happy Ending. It uses tunneling [18,39], has both pull (Web page) and push elements (e-mails and short message service [SMS] messages), and delivers program materials through the "voice" of a nonembodied relational agent [11]. Importantly, lapse management (with Marlatt's cognitive behavioral model of relapse prevention [10] as methodological counterpart) is a central component of both Endre and Happy Ending. However, as opposed to Happy Ending, which in addition to lapse management consisted of a large number of theoretical and methodological underpinnings [34], the content of Endre is centered on 2 other theoretical concepts: internalized motivation (with MI as the methodological counterpart [26,27]) and working alliance (with alliance factors [13] as the methodological counterpart).

Endre consists of 26 tunneled [18,39] Web sessions. On registration, users provide their mobile phone number and e-mail address, which prompts receipt of an automatically generated e-mail with a username and password. After the program starts, the user goes through 10 days of preparing to quit with one new session each day, followed by their quit day, which is scheduled on the 11th day. The user must confirm a quit attempt before the program moves on to the follow-up phase. In the follow-up phase, the user gets one new session the first 3 days, then 2 new sessions every week for the first 4 weeks, and finally one new session a week for the last 4 weeks. The program ends 8 weeks after the cessation day. Automatically generated e-mails give the user access to each new session through a link. The links are time based, they lead to today's session for that individual user, and one cannot access earlier sessions by clicking on old links. If a user rarely logs on, he or she will only receive the

most important missed sessions. An overview of the themes for each session can be viewed in Multimedia Appendix 1 .

Endre provides no additional human support. Most sessions involve user interactivity, requesting input from the user (see screenshots below for examples). We anticipate that an adult, typical user with average reading abilities may spend 4-6 minutes on each session. The user receives synchronous and immediate feedback on input. The lapse management component of Endre is based on the lapse management component in Happy Ending [34] and consists of daily SMS messages that are sent out to users who have quit, asking them if they have been smoke free that day. If the user reports a lapse, he or she gets access to a special, Web-based session intended to help the user recover from the lapse (Multimedia Appendix 2). This special session can be accessed whenever and for as many times as necessary.

\section{Analytic Procedure}

We describe how a counselor's support of a working alliance, internal motivation, and lapse preparation and management are simulated in Endre by using selected steps from the intervention mapping protocol (steps 2, 3, and 4) [38]. Intervention mapping is well suited for describing process simulation because it can be applied to understand the program construction. Furthermore, the necessary information for an intervention mapping analysis was readily available, as Endre was developed using intervention mapping. Intervention mapping is conventionally used to describe everything in a program $[29,30,40-50]$. Contrarily, we use it in a focused way to describe only the elements that are relevant to our hypothesis of important program elements. The intervention mapping tools are thus used for an analysis consisting of 2 parts: First going from general therapeutic process to theoretical operationalization suiting the context of this program; and second, going from theoretical operationalization to simulation in specific program elements.

First, we describe how supporting a working alliance, internalized motivation, and lapse preparation and management are operationalized in Endre 's theoretical change model (step 2 in intervention mapping [38]). In the change model, the changes necessary to quit smoking by means of Endre are 
described and displayed in a matrix. In the intersecting cells of the matrix, the operationalization of each therapeutic process is described in a list of change objectives. That is, each change objective shows how one aspect of one of the therapeutic processes is operationalized for the purpose of the intervention (that the user quits smoking and stays smoke free with Endre) and its context (a fully automated program). An analytic text accompanies the change model to describe how the 3 processes are represented in the change model. The change model that was used for the development of Endre (Multimedia Appendix 3 ) is simplified to highlight the 3 therapeutic processes, and we use sequential numbering of the change objectives instead of conventional intervention mapping-labeling [38] to improve readability outside of the intervention mapping community. The change model operationalizes the abstract and general therapeutic processes. It is therefore the first part of the analysis toward the processes' simulation.

After showing how supporting a working alliance, internalized motivation, and lapse preparation and lapse management are operationalized through change objectives, we describe how the 3 therapeutic processes are simulated through specific program elements (steps 3 and 4 in intervention mapping [38]). The program elements result from combining change objectives with theoretical methods for inducing change (eg, MI, modeling). This second part of the analysis takes the (theoretical) operationalizations of the 3 therapeutic processes and makes them into (practical) simulations through specific program elements.

\section{Results}

\section{Operationalization of the Therapeutic Processes in Endre}

The operationalization of the therapeutic processes can be viewed in the change model matrix (Table 1). In the matrix, sub-behaviors in quitting, or performance objectives, are crossed with theoretical constructs, or personal determinants, believed to be causing or influencing the behavior. Each therapeutic process is represented within the model either as a personal determinant or a performance objective. The personal determinants and performance objectives intersect in cells containing change objectives, which specify how each personal determinant must change for the individual to be equipped to do each performance objective.

Working alliance and internalized motivation are operationalized as personal determinants, whereas behavior maintenance through lapse preparation and lapse management is operationalized as a performance objective. Having a working alliance to the program is not a necessary psychological process for quitting smoking in general. It might, however, be an important process for quitting smoking with the help of Endre, if one assumes that a successful simulation of supporting a working alliance can have the same benefits for therapy outcome in a fully automated program as it has in face-to-face counseling [7,8]. Though a working alliance can be an important psychological process for quitting smoking with Endre, internalized motivation is an important psychological process for succeeding in quitting smoking at all. In the model, internalized motivation is separated into the underlying personal determinants relatedness, competence, and autonomy; the 3 "needs" that influence the internalization of motivation [9]. Competence is itself separated into 2 personal determinants: skills and self-efficacy. As with competence, relatedness is also separated into 2 personal determinants: relatedness to social network and working alliance. Working alliance, or relatedness to the program, is included under relatedness because a positive counseling relationship can also support the client's (or user's) need for relatedness [27]. In contrast, behavior maintenance through lapse prevention and lapse management is operationalized in the change model as a performance objective, meaning that managing lapses in a constructive way is considered an important subgoal for succeeding in quitting smoking. The change objectives belonging to each therapeutic process is the operationalization of that process for the purpose of this program. 
Table 1. Modified change model. ${ }^{\mathrm{a}}$

Performance objectives Personal determinants

Internalized motivation (therapeutic process 2)

Relatedness

Working alliance (therapeu- To social network tic process 1)

1. Decide to quit smok- 1 . Experience the program ing and plan how to do as a social actor [11] it.

2. Experience the program as accessible, helpful, empathic, and trustworthy [13].

3. Be aware of one's influence on program content [13].

4. Understand how to use the program and do the exercises [13].

2. Initiate the quit attempt and stay smoke free for the first 3 days. sensitive, and adjustable for emerging needs and (2) suiting one's own preferences and style [13].
5. Make a public commitment to the quit attempt.

6. Choose a "support person" from one's personal network. $-$

se

(n)




\section{Simulation of the Therapeutic Processes in Endre}

In this section, we describe how the therapeutic processes are simulated in Endre. For each therapeutic process, we present program elements that are involved in the simulation and describe the methods that are used. To support working alliance we adapted MI [24] to a computerized "counselor" who delivers all program material through what we refer to as computerized motivational interviewing (cMI). The "counselor" is called Endre, which has a double meaning in Norwegian, being a man's name, as well as literally meaning "to change." Internalized motivation is primarily supported through cMI, whereas behavior maintenance is strengthened with a psycho-educative session before the quitting day, as well as a special Web-based session that is made accessible if the user reports a lapse. If the user experiences several lapses, this is recognized by Endre, and the content of the session is adjusted accordingly.

\section{Simulation of Working Alliance Support}

Working alliance is supported in program elements using a nonembodied relational agent [12], cMI (Multimedia Appendix 4), and dynamic tailoring [42] to convey alliance factors [13]. For the users to experience the program as a social actor [11] (change objective 1) that is accessible, helpful, empathic, and trustworthy [13] (change objective 2), the relational agent [12] Endre is used throughout the program. Endre is a nonembodied, text-based relational agent that simulates a "counselor" the user "communicates" with. Some key attributes of Endre can be found in Textbox 1, and examples of how "he" is represented in the program can be found in Figures 2-6.

Textbox 1. Attributes of the relational agent Endre.

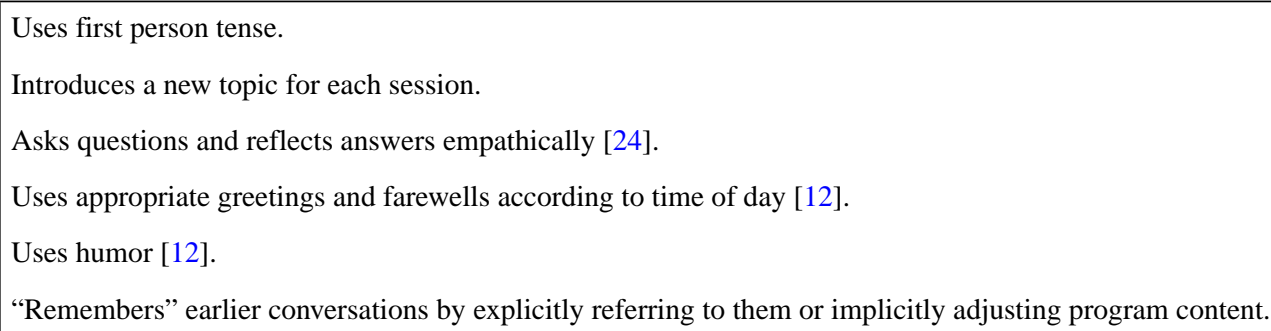

To further support a working alliance, users are allowed to influence the program content [13] (change objective 3). This is a way of "negotiating" goals [13] and is done in the first session (Figure 2). After Endre has presented the program plan, the user is asked to choose a topic he or she considers important when quitting. On the subsequent page, Endre assures the user that "he" will make time for this topic during the course of the program. The user's topic is visited 2 times during the program.

To build a working alliance to the user, it is also necessary for him or her to receive guidance in how to use the program [13] (change objective 4). Endre provides guidance to the user, for example by explaining how new sessions are made available and how the user can log onto them. In addition, new program exercises are demonstrated by four fictional "quitters" (Figure 3).

Working alliance is further strengthened if the program is experienced as responsive, sensitive, adjustable for emerging needs, and suiting one's own preferences and style [13] (change objective 16). To address this, Endre has a flexible session manager (Textbox 2) that adjusts the total number of sessions to user behavior. This means that a user who does not log on to the program every time a new session is available will only receive the most important sessions, limiting the total number of sessions for that particular user.

Textbox 2. Flexible session manager.

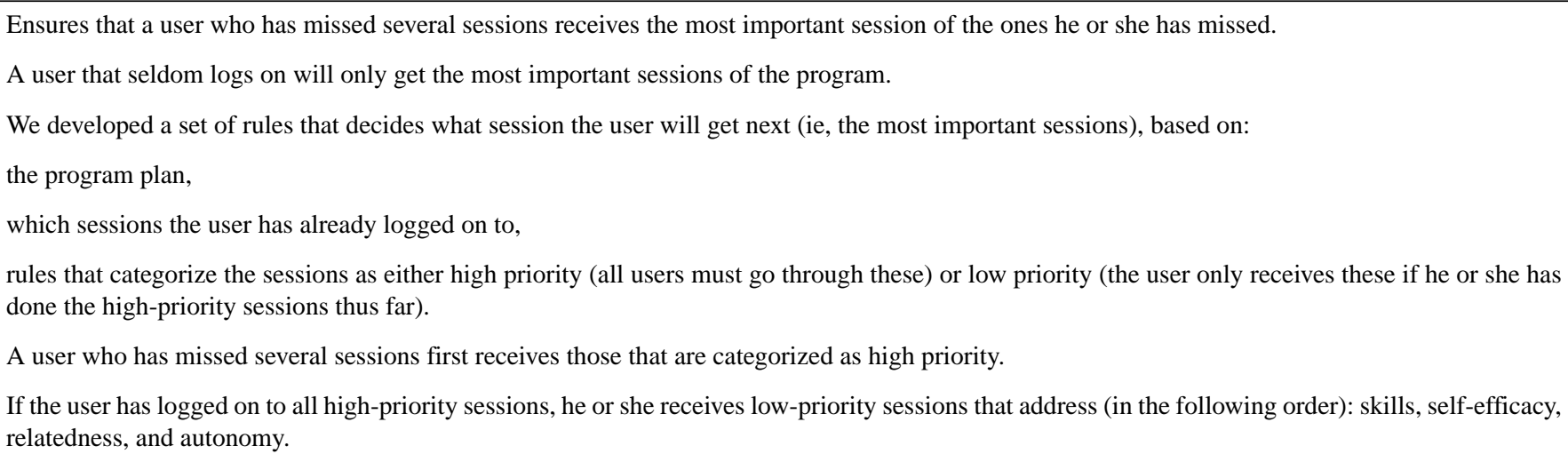

A final program aspect supporting working alliance is a "mini motivation intervention" (Textbox 3), consisting of SMS messages and intended to prevent program disengagement (alliance "rupture" [13]) (change objective 25). 
Textbox 3. Mini motivation intervention.

Before quitting day:

If the user misses one session, nothing happens.

If the user misses 2 sessions, he or she gets an SMS message from Endre, reminding him or her to log on.

If the user misses 3 sessions, he or she gets an SMS message where Endre normalizes having second thoughts and recommends logging on to the program.

If the user misses a fourth session, nothing happens.

If the user misses a fifth session, he or she gets a final SMS message where Endre appeals to the "healthy part" of the user to log on.

After quitting day:

After quitting day, there is no intervention if the user does not log on to the Web page.

A part of the lapse management system is that the user every evening receives an SMS message, asking if he or she has been smoke free. If the user does not answer the SMS message, he or she will receive up to 3 extra SMS messages encouraging him or her to answer.

Figure 2. Choosing a topic ("negotiating" goals).

BNDRE Konto -

\section{Your turn}

Which one of these topics do you think we should spend a little time on as we work on quitting smoking?

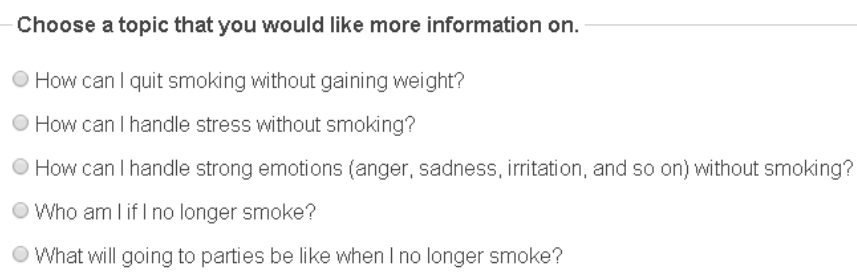

Figure 3. The 4 "quitters" demonstrate how to do the program exercises and model how to combine Endre's advice with one's own personal style.

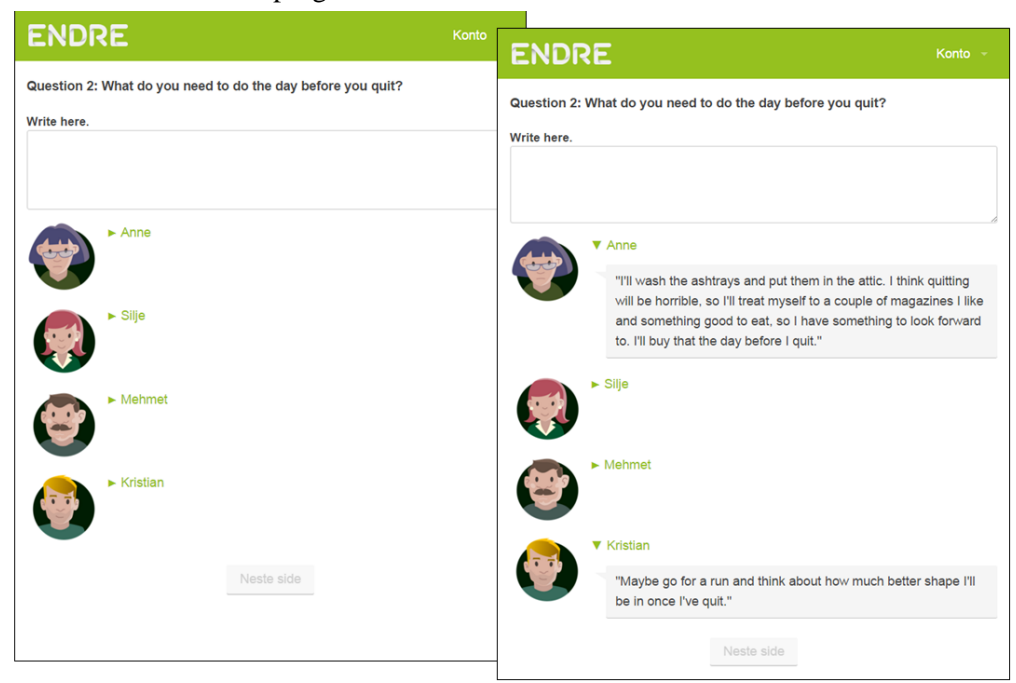


Figure 4. Eliciting self-efficacy change talk through a confidence ruler.

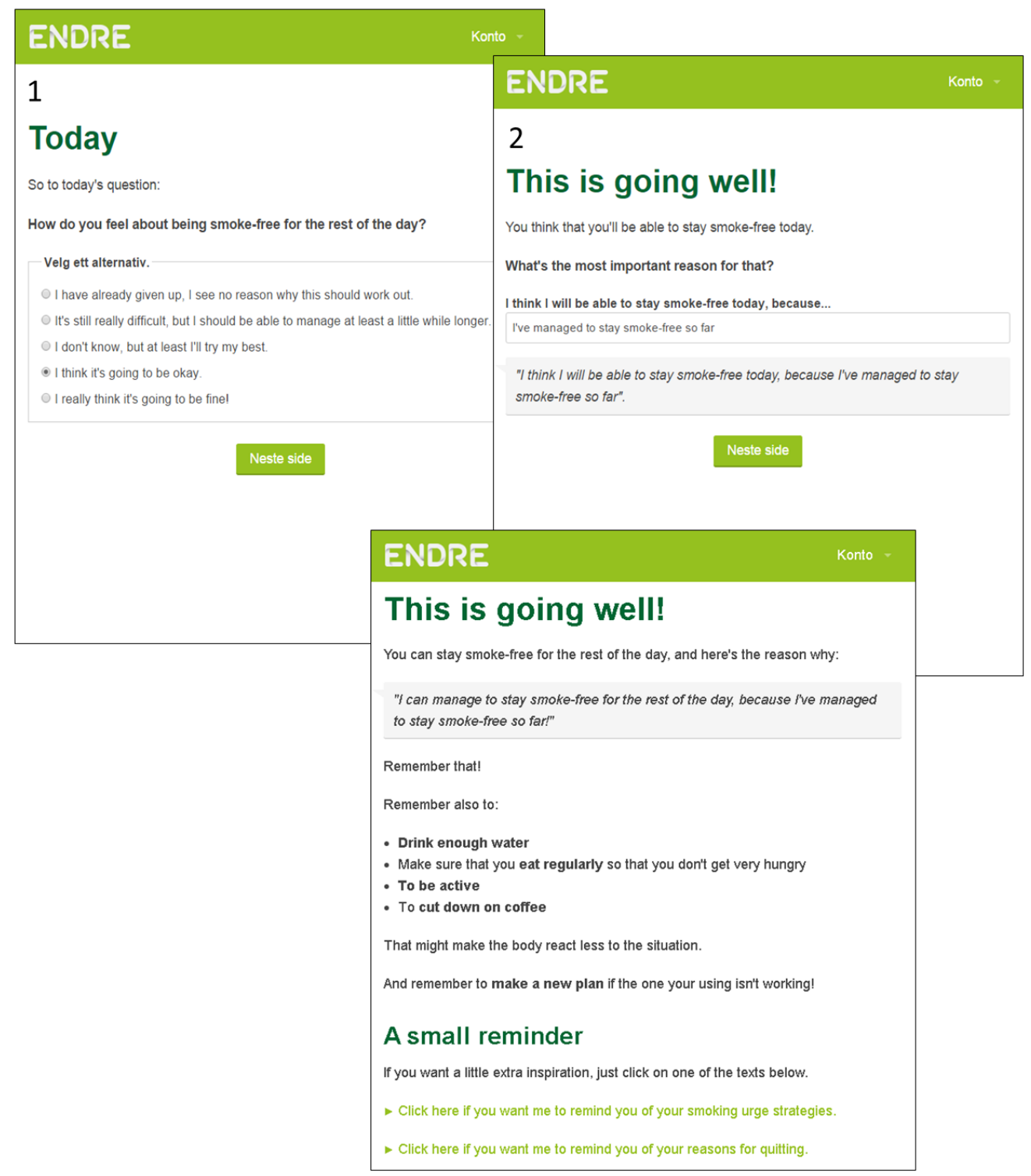

Figure 5. Endre has asked the user to choose a "support person" for her quit attempt, and the user has answered that he or she wants to quit without any help.

\begin{tabular}{|c|c|}
\hline ENDRE & ENDRE \\
\hline 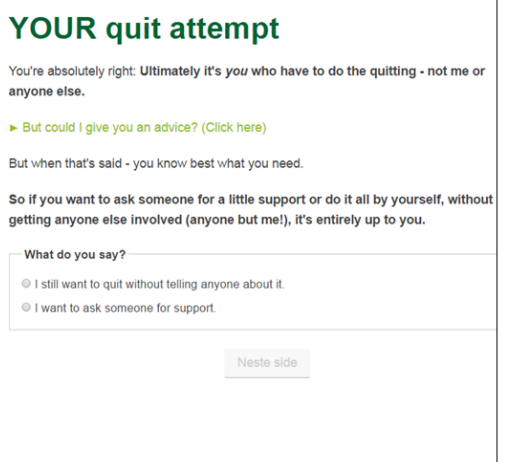 & 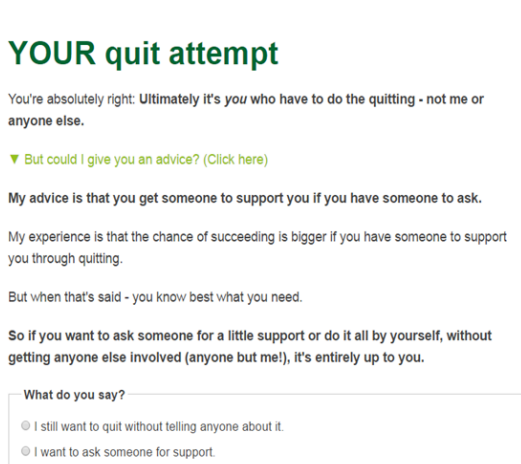 \\
\hline & Neste side \\
\hline
\end{tabular}


Figure 6. Handling sustain talk and discord.

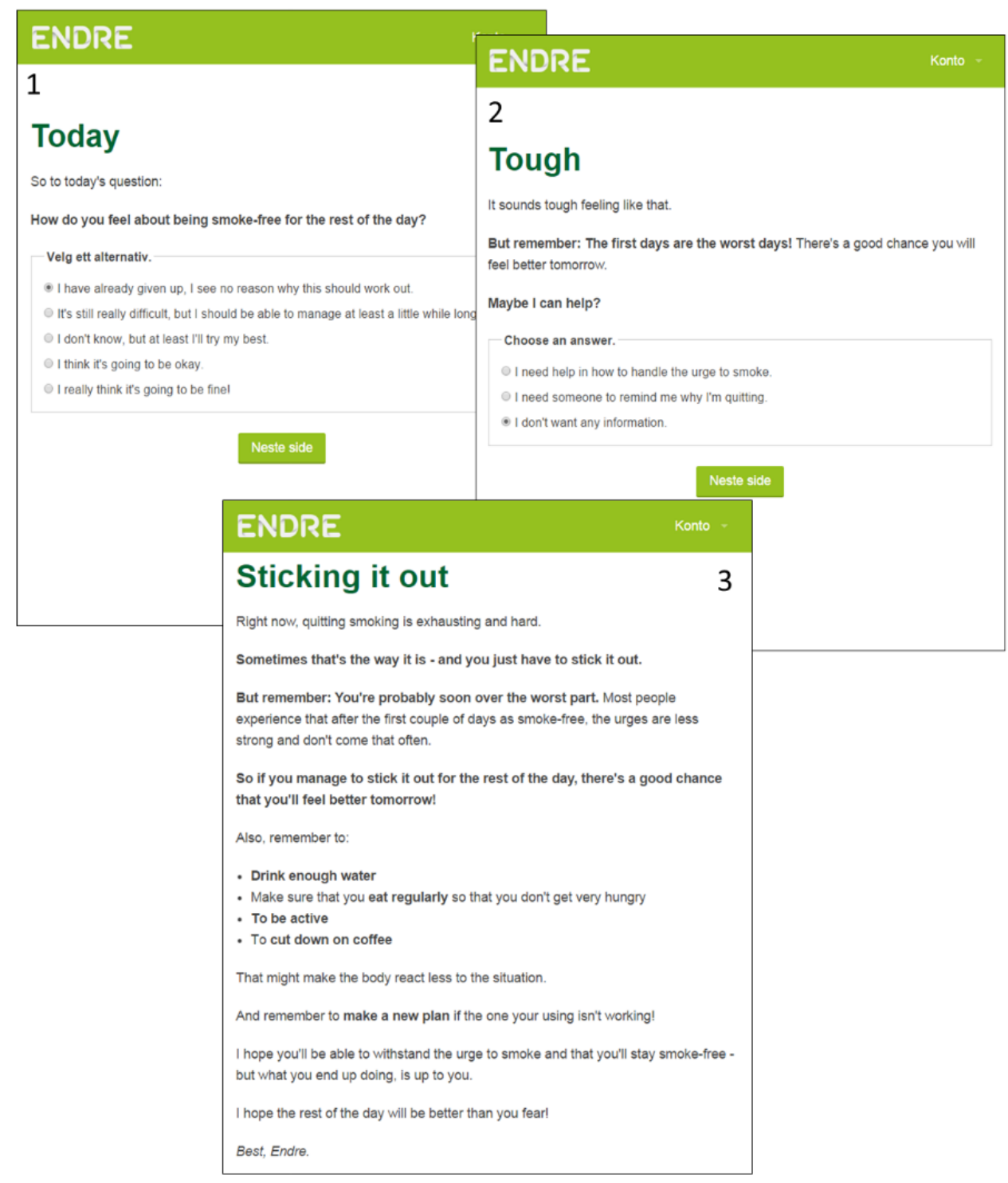

\section{Simulation of Internalized Motivation Support}

Internalized motivation is achieved through Endre strengthening the user's autonomy, competence, and relatedness [9]. Relatedness is partly supported through building a working alliance between the user and the program, as described in the previous section. The other part of relatedness, relatedness to social network, is strengthened through helping the user find support in the people surrounding him or her. This is done by advising the user to recruit a "support person" from his or her social network (change objective 6), advising him or her to make the quit attempt public (change objective 5), and guiding the user in how to make their "support person" have the greatest positive impact on his or her quit attempt (change objective 17). Figure 5 is from the session where Endre advices the user to choose a "support person," showing what happens when the user does not want to follow Endre 's advice. Another way in which Endre supports the user's relatedness to his or her social network is effectuated if the user reports a lapse after he or she has quit. Endre then asks if this lapse may affect the user's relationship to his or her social network. If the user answers yes, Endre offers help to ensure the social network's continued support for the quit attempt (change objective 30). All advice is given using cMI (Multimedia Appendix 4) and dynamic tailoring [42].

Autonomy is supported in program elements using cMI, dynamic tailoring [42], and modeling [38]. One way Endre supports autonomy is by asking for permission before giving any information or advice (Textbox 4). This is a way of acknowledging that the user chooses what information to receive. Asking for permission is relevant to change objectives $13,15,23$, and 24 . 
Textbox 4. Asking for permission.

Endre requires one of two actions from the user before giving any information or advice:

Hide/show text: The user can choose whether or not to click on the question (eg, "do you want me to tell you about...") to reveal the information. An example can be viewed in Figure 3.

Question + multiple choice yes/no: The user must answer yes or no when Endre asks for permission to give information or advice; if the user answers yes, the information is revealed on the next page. For example, one session starts by Endre introducing today's topic, and then asking the user whether he or she thinks this sounds okay. If the user answers yes, the session continues. If the user answers no, the session is ended.

A second way in which autonomy is supported is through handling sustain talk (reasons for smoking) and discord (dissatisfaction with therapy) [24] respectfully. Sustain talk and discord may be expressed by the user at select places in the program through multiple-choice alternatives. The fact that expressing sustain talk or discord is allowed (even when it goes against the program) communicates respect for the user's autonomy. If sustain talk or discord is expressed, Endre repeats the user's feelings empathically, and then, depending on the situation, asks more questions, normalizes, offers help, or changes the topic [24]. Handling sustain talk and discord is relevant to change objectives $13,15,23,24$, and 35 . An example of how sustain talk or discord may be expressed and how it is handled can be seen in Figure 6. This is from the user's second day as smoke free. On page 1, Endre asks the user how he or she feels about staying smoke free for the rest of the day. The example shows the user choosing the statement representing the lowest degree of self-efficacy; so low that it qualifies as sustain talk. On page 2, Endre offers help. The user chooses that he or she does not want any help; this can be seen as dissatisfaction with the program, or discord. On page 3, Endre reflects empathically and normalizes the user's feelings.

A third way Endre supports the user's autonomy is through eliciting and reflecting change talk, that is, talk arguing toward change [24] (change objective 12). Change talk is the user's autonomous reasons and capacities for quitting and is requested throughout the program. Endre repeats the user's change talk and sometimes elaborates on it. For example, in one session, Endre asks the user for his or her most important reason for wanting to become smoke free (eliciting change talk). Endre repeats the user's most important reason on the next page (reflecting change talk). Asking for permission, handling sustain talk and discord, and eliciting change talk is achieved through cMI and dynamic tailoring [42], and details of these applications can be viewed in Multimedia Appendix 4.

A fourth and final way in which Endre supports autonomy is through modeling [38]. In the program, 4 fictional "quitters" model autonomy by illustrating how to combine the advice of the program with one's own style and preferences (change objective 15). The 4 "quitters" are of different gender, age, socioeconomic status, cultural background, and smoking profiles [53]. The "quitters" answer Endre's questions and tasks in ways that suit their situation and personality. An example of this application can be viewed in Figure 3. This screenshot is from the session for making a cessation plan, where Endre asks the user what he or she needs to do the day before quitting. By clicking on the names of the 4 fictional "quitters," the user may read "their" answers.
Autonomy is supported through asking for permission before giving advice, handling sustain talk and discord respectfully, eliciting and reflecting change talk, and modeling how to combine the program's advice with one's own preferences and style. Competence is supported through increasing the user's quit-related skills and increasing his or her self-efficacy for quitting. Skills can be acquired through the general information and advice that Endre gives, as well as through program exercises. For example, before quitting day, Endre asks the user to spend a few days thinking about what precedes his or her smoking — what are his or her smoking cues. After a few days, Endre asks the user for these smoking cues. This teaches the user to be attentive to what triggers the urge to smoke. The advices and exercises that Endre gives are based on self-monitoring of behavior, counter-conditioning, active learning, goal setting, planning coping responses, and implementation intentions [38], always communicated using cMI (Multimedia Appendix 4).

Whereas skills are supported through information, advice, and exercises, self-efficacy is supported through cMI techniques, in combination with dynamic tailoring [42]. The user's self-efficacy is strengthened through "confidence rulers" [24,32]. An example of this application can be found in Figure 4. These screenshots are from the same session as the ones in Figure 6, but showing what happens when the user answers differently. In this example, the user chooses the statement reflecting a quite high degree of self-efficacy. On page 2, Endre asks the user to justify why he or she chose that statement over a statement representing a lower degree of self-efficacy. The user types in his or her answer, and on page 3, this statement is reflected back to him or her. The user has argued for change and had the argument reflected back, amplifying the effect [24].

Self-efficacy is also strengthened through affirmations [24], that is, compliments on the user's strengths and accomplishments. For example, in one session, the user is asked if he or she has tried quitting before. If the user answers yes, Endre replies that this is a good thing, because the user then has experience that he or she can use to increase the chances of succeeding this time. Turning previous quitting experience into something positive is a way of providing affirmation, supporting self-efficacy, competence, and internal motivation.

\section{Simulation of Lapse Preparation and Lapse Management Support}

Behavior maintenance is supported through a psychoeducative session before the user's quit day and a lapse management component after he or she has quit. First, a psychoeducative session on lapses and relapses prepares the user to respond constructively in case of a lapse (change objectives 31 and 35). 
In this session, a car puncturing a tire is used as a visual analogy [38] for lapsing and relapsing. The cars can be seen in Figure 7. Car no.1 illustrates the lapse (puncturing the tire), car no. 2 illustrates a relapse (giving up and succumbing to negative emotions), car no. 3 shows the process of choosing, car no. 4 is acting to resume the quit attempt, and car no. 5 illustrates being smoke free again.

In the preparatory session, the user is also presented with an advance organizer [38] of the process of becoming smoke free again after a lapse. The advance organizer has the shape of a circle (Figure 8) displaying the self-regulation loops [54] that can help the user back to being smoke free. First, realize that you are smoking ("innse"), then choose: Keep smoking or keep quitting ("velge"), then act to become smoke free again ("handle"), and finally continue with being smoke free ("fortsett"). The information is given with cMI (Multimedia Appendix 4).

Following up on the preparatory session on lapses and relapses is a lapse management component which is effectuated after the user has confirmed a quit attempt. Every day, the user receives an SMS message asking if she is still smoke free. If the user answers yes, another SMS message compliments the user's accomplishment. If however the user answers no, he or she receives an SMS message with a link to a Web-based lapse management session. The user may access the session through the SMS message; if he or she does not log on via the SMS message, he or she receives the lapse management session when logging on to the program next time. The lapse management session helps the user make a choice, become smoke free again and learn from the lapse. When logging on to the Web-page, the user is first reintroduced to the car (Figure 7) and the circle (Figure 8). Endre then asks if the user has already decided what to do: keep quitting or keep smoking (Figure 9). If the user chooses to keep quitting, Endre guides him or her back to being smoke free, helps making a new plan on how to face a similar situation in the future without lapsing, and supports the user's belief in his or her ability to stay smoke free. Figure 9 shows a screenshot from the lapse management session. In this example, Endre has asked the user if he or she knows what to do now, and the user has answered that he or she is unsure. On the next page, shown in the screenshot, the user may choose which topic he or she wants Endre to start with (the picture does not show the entire page). Asking the user what topic to start with is a way of asking for permission [24], strengthening his or her autonomy and supporting internal motivation. In addition, letting the user influence the program structure influences the working alliance positively [13]. This screenshot shows the main topics that are covered in the lapse management session: reattribution [10], ambivalence [24], the abstinence violation effect [10], and making a choice. Only users who express ambivalence or an abstinence violation effect when asked go through these topics. Multimedia Appendix 2 contains more information on the lapse management component, including a flow chart that shows the different ways in which this session may be built up. Some of the methods that are used are cMI (Multimedia Appendix 4), dynamic tailoring [42], reattribution [55], and cognitive restructuring [56].

Figure 7. Visual analogy for lapsing and resuming the quit attempt.
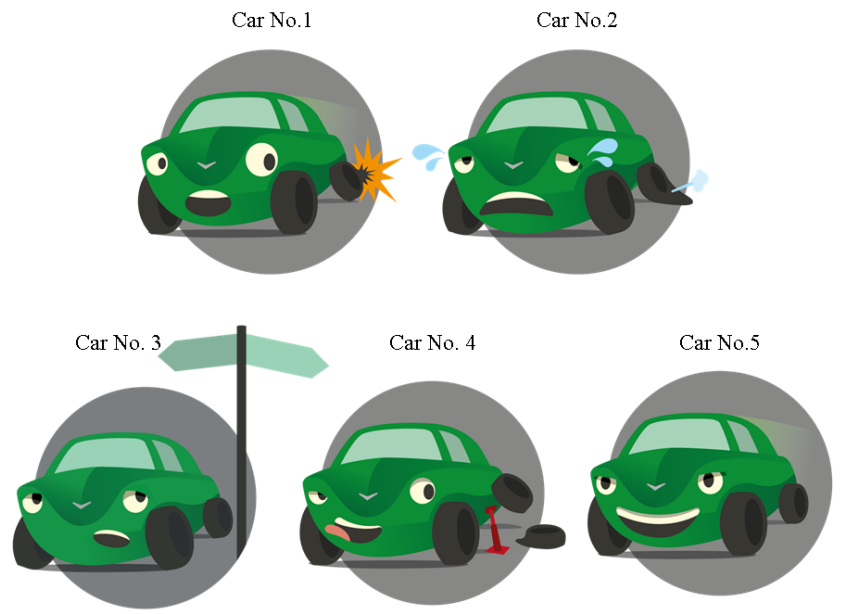
Figure 8. Advance organizer of returning to the quit attempt after a lapse (from top left section): realize ("innse"), choose ("velge"), act ("handle"), and continue ("fortsett").

ENDRE Konto -

\section{Lapse and relapse}

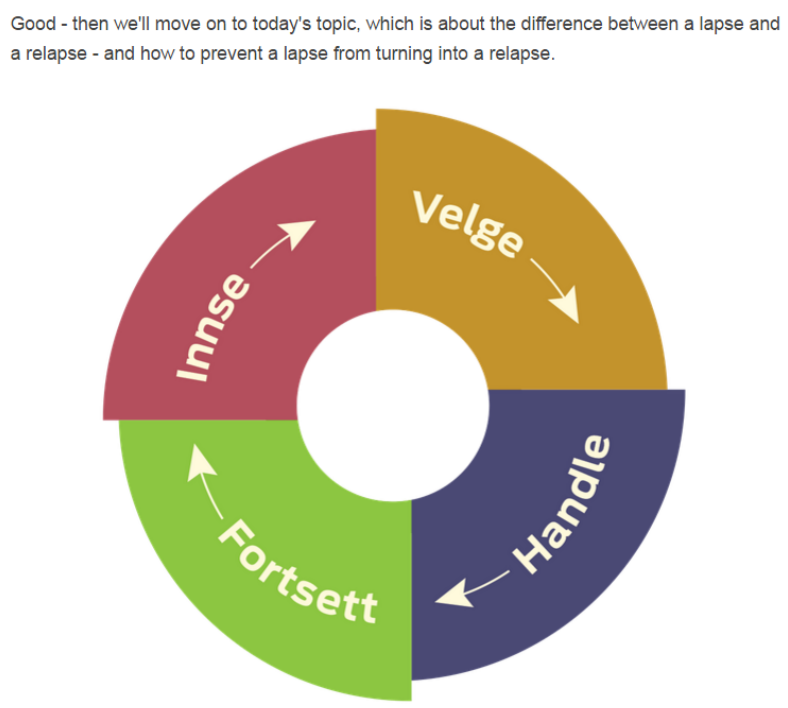

\section{REALIZE - 2. CHOOSE - 3. ACT - 4. CONTINUE}

If you should find yourself in a situation where you've had a smoke after you've quit, I hope you'll remember these four words. They describe the four things you have to do to prevent a lapse from turning into a relapse.

Figure 9. From the lapse management session: the user is unsure of what to do and is asked what topic to begin with.

I always think that having a cigarette after you've quit is kind of like puncturing a tire when
you're out driving.
- It might seem like you've come to a full stop.
Pouve to decide what you want to do to solve the situation.
Puncturing isn't fun, one would rather avoid it. But the cigarette you had and the
punctured car have one important thing in common:
What you choose means everything. To smoke or be smoke-free, to change the tire or
not.
The rest is, to be a little blunt, secondary.
I can help you find out how to go from here.
What's most important for you right now?
O I need to understand what went wrong. What happened?
O I don't knowif I want to keep quitting or not.
I just want to give up, I feel hopeless and don't think l'll ever be able to quit.
I just want some practical advice. What do I do now?

\section{Discussion}

\section{Summary Analysis}

This case study illustrates our proposed theoretical model for eHealth behavior change interventions: simulating a counselor's support of working alliance, internalization of motivation, lapse preparation, and lapse management simultaneously. The case, Endre, is a fully automated smoking cessation program where each session takes the form of a written "counseling session" between the user and the program. The program content and structure were analyzed using intervention mapping [38], 
illustrating the translation from theoretical model to intervention. The analysis shows that simulation of the 3 therapeutic processes is accomplished through a range of program elements. Working alliance [7,8] is supported through alliance factors [13], a nonembodied relational agent [12],cMI (Multimedia Appendix 4), and dynamic tailoring [42]. Internal motivation [9] is supported through cMI, dynamic tailoring, and modeling [38]. Finally, relapse is sought prevented through a psychoeducative session on lapses and relapses and a postquit day lapse management component.

By defining the components of a program and discussing its potentials for interactivity and tailoring in terms of concepts from face-to-face counseling, eHealth programs can be better understood [6]. This has implications both for program development and for the theoretical development of eHealth therapeutic process. In addition, by showing how the therapeutic processes of a program can be documented, from abstract concept through operationalization to simulation in specific program elements, we have demonstrated how intervention mapping used in a focused manner provides a compelling, interpretative approach to eHealth case studies. The value of such an inquiry for future empirical investigation is substantial: If the intervention should prove not to be effective, this may be because the identified theoretical processes are not sufficient for supporting behavior change or because the translation from theory to intervention elements was less than optimal.

The analysis of Endre suggests that the simultaneous simulation of each therapeutic process may result in a synergy effect. The operationalization in Table 1 reveals some of these potential interaction effects. The table visualizes that a working alliance is also a part of internalized motivation. When a working alliance to Endre is supported, this can influence the user's need for relatedness, thus supporting his or her internalized motivation to quit [27]. In addition, Table 1 visualizes that a working alliance and internalized motivation (columns) cross behavior maintenance (row). This means that for Endre to succeed in helping the user manage lapses, he or she needs to have both a working alliance to Endre and internalized motivation to recover from a lapse, demonstrating that lapse management in a fully automated program can benefit from a strong working alliance and internalized motivation. A strong working alliance may enhance the effect of a lapse management program element through facilitating client processes such as commitment, satisfaction, and trust [23].This may increase the likelihood of the user staying with the program long enough to benefit from the lapse management therapy and trust the therapy that is given. At the same time, internalized motivation increases self-regulation, performance, and persistence $[9,27,28]$ and may function as a buffer for future lapses. Should the user experience a lapse, a program that is supportive through that difficult period is likely to strengthen the working alliance by demonstrating sensitivity to the user's changing needs [23]. Furthermore, if the user should succeed in overcoming the lapse it would also presumably increase his or her feeling of competence, again enhancing internalized motivation [27]. It seems therefore that simultaneous simulation of supporting a working alliance, internalized motivation, and lapse management may result in a mutual enhancement of each process. These hypothesized synergy effects are displayed in Figure 10.

Interaction can be assumed from the operationalization level, but the step to simulation also shows the many methods and program elements that support several therapeutic processes at once. For example, all program material is delivered by the relational agent Endre using cMI. A relational agent supports working alliance [12], and cMI supports both working alliance [25] and internalized motivation [26], but in different ways. Endre also uses cMI in the lapse management session, influencing all 3 therapeutic processes at once. Another example of a program element that support several therapeutic processes are the 4 "quitters," serving both as guides in how to do the program exercises (supporting a working alliance) and as models in how to exercise autonomy in the quitting process (supporting internalized motivation). The fact that many program elements support several therapeutic processes at once implies that the effort needed to incorporate more than one therapeutic process in a program may diminish for each process included. 
Figure 10. Hypothesized synergy effects of the 3 therapeutic processes.

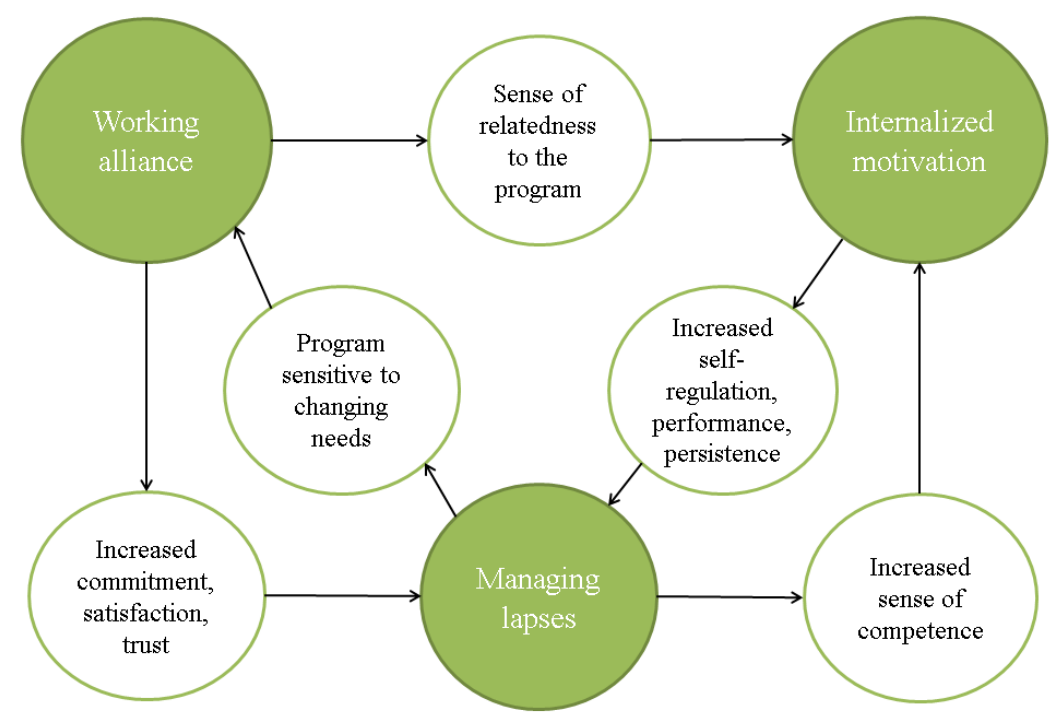

\section{Comparison with Prior Work}

All 3 therapeutic processes have been applied to fully automated programs previously. Studies on working alliance have mostly been on relational agents $[11,12]$. Endre builds on this work, although applying a nonembodied, rather than embodied relational agent, allowing the user freedom to "create" aspects of the relational agent. To further support a working alliance, Endre also incorporates alliance factors [13]. "Endre" also builds on previous work in the application of MI [32,33] and use of lapse preparation and lapse management [31,34-37]. The most significant contribution of Endre, however, is simulating all 3 processes simultaneously, something that to the best of our knowledge has not been done before systematically in a fully automated eHealth program.

Finally, this paper extends earlier work using intervention mapping eHealth tools to present a focused descriptive analysis of chosen program elements. Papers that use intervention mapping usually follow the structure of the intervention mapping steps and reports on most of these [29,30,40-50]. Instead of giving a full account of the breadth of the program, this paper uses intervention mapping for a focused descriptive analysis to make an argument of possible important eHealth elements. The description is intended to be sufficiently deep to allow for further inquiry into the chosen elements. This application of intervention mapping represents a complementary approach to the standard use of the method, that is, instead of using intervention mapping as a purely descriptive tool, we use it as a normative tool to determine what elements should be present in the "black box" of eHealth programs.

\section{Limitations}

Although comprehensive, the analysis presented here is a simplification of how the 3 therapeutic processes are simulated in Endre. Especially the social behavior of the relational agent, cMI, and dynamic tailoring are elements that are used in the entire program, and a full account was therefore not possible. Another limitation is that to highlight the 3 therapeutic processes, descriptive depth was chosen over descriptive breadth. In addition, Endre does not simulate the 3 therapeutic processes perfectly. A fully automated program neither has the flexibility nor the presence of an actual human being. Just as Endre is not a human counselor, cMI is not MI. But the program may nevertheless simulate these 3 therapeutic processes convincingly enough to derive some of the benefits they have in face-to-face counseling. It should also be noted that Endre only represents one way in which these therapeutic processes may be simulated. Thus, if Endre fails to be an efficient program, it may be because the therapeutic processes in a fully automated program are not successful in inducing change or because the simulation of the therapeutic processes in Endre was inadequate.

There are, of course, limitations to the type of program that Endre represents. First, not everyone who wishes to quit smoking may benefit from such a detailed program. In the first author's clinical experience, some simply quit and do not wish to spend more time elaborating on the process. A participant in an earlier study conducted by the third author [57] actually experienced late night SMS messages asking whether she had been smoke free that day as smoking cues, creating a risk of (re)lapsing. Endre does make it possible for "unproblematic" quitters to move through many of the sessions rapidly, and the flexible session manager makes it possible to complete fewer sessions than what is in the full program. Nevertheless, it is a quite extensive intervention, communicating an expectation that quitting smoking is a process instead of a one-time action and requiring answers to daily SMS messages. Second, not everyone may wish to convey their thoughts with a program. Efforts to simulate a therapeutic setting aside, the therapy may still seem too artificial and ultimately unconvincing to the user. Alternately, the simulation may be too convincing, and sharing one's personal thoughts on quitting smoking with a machine that responds empathically to one's input may create an "uncanny" feeling [58] because the program acts like a human without being one. Even though reports from users of Endre so far indicate to the contrary that they respond positively to the 
"mixture" of Man and machine, this is an area that will require further research.

\section{Future Directions}

Endre and the theoretical model presented here will be evaluated in forthcoming studies. Because the application of the model to the program is made explicit, it is possible to test. Empirical investigations may in turn influence or alter the theoretical model or its recommended application to a program.

In one current Randomized Controlled Trial (RCT), the lapse management component will be evaluated by randomly allocating participants to one version of the program with the lapse management component and one version without it. The results of this RCT will tell us whether providing immediate help to users who have had a lapse can significantly improve their success rate. We also plan to collect indicators on working alliance and on internal motivation.

Another ongoing project is a qualitative study on the users' working alliance to Endre. The goal of this study is to explore the nature of the working alliance because it is not given that working alliance to a fully automated program is identical to the working alliance to a human therapist. It is only when we can be convinced of the nature of working alliance to a fully automated program that it will be truly meaningful to test its importance for eHealth-assisted behavior change.
Finally, although we have argued that Endre simulates support of a working alliance, internalized motivation, and lapse preparation and lapse management, we do not know to what extent this simulation is successful for the user. One might establish simulation success through RCTs as the one described previously and compare the results with comparable findings from the counseling literature.

\section{Conclusions}

We have demonstrated how Endre, a fully automated eHealth program, through interactivity and individual tailoring emulate 3 effective mechanisms of face-to-face counseling. By having used intervention mapping to systematically break down Endre into smaller components and showed how the program simulates a counselor's support of a working alliance, internalized motivation, and lapse preparation and lapse management, our analysis is an example of how knowledge of what works in eHealth programs may be deepened by interpreting them in light of therapeutic processes. We suggest that the combination of these 3 therapeutic processes may result in a synergistic effect. Based on the analysis, we believe the combined support of a working alliance, internalization of motivation, and lapse preparation and management should be an element in the "black box" of automated eHealth behavior change programs that will make them more effective.

\section{Acknowledgments}

Endre was developed by the authors, at the Norwegian Centre for Addiction Research (SERAF), University of Oslo, Norway. The project is financed by the Norwegian Research Council. The authors have no financial interest in the program. Endre runs on secure servers and data transmission is encrypted. Endre is developed for research purposes and is currently not available to the general public.

Thank you to InOnIt for developing the computer software to meet our needs for developing Endre, and to Miksmaster for designing the program interface, and for making the logo and illustrations. Thanks to Brian Danaher, at Oregon Research Institute, for valuable input to intervention design. Thanks also to Stijn Friederichs for inspiring conversations about MI in automated programs, and to Desiree Madah-Amiri for proof-reading the final manuscript.

\section{Conflicts of Interest}

None declared.

\section{Multimedia Appendix 1}

Overview of the themes in Endre.

[PDF File (Adobe PDF File), 366KB-Multimedia Appendix 1]

\section{Multimedia Appendix 2}

The postquit day lapse management component of Endre.

[PDF File (Adobe PDF File), 345KB-Multimedia Appendix 2]

\section{Multimedia Appendix 3}

Change model from the development of Endre.

[PDF File (Adobe PDF File), 216KB-Multimedia Appendix 3]

\section{Multimedia Appendix 4}

Computerized motivational interviewing in Endre. 
[PDF File (Adobe PDF File), 476KB-Multimedia Appendix 4]

\section{References}

1. Kok G, Mesters I. Getting inside the black box of health promotion programmes using intervention Mapping. Chronic Illn 2011 Sep;7(3):176-180. [doi: 10.1177/1742395311403013] [Medline: 21900338]

2. Michie S, Abraham C, Eccles MP, Francis JJ, Hardeman W, Johnston M. Strengthening evaluation and implementation by specifying components of behaviour change interventions: a study protocol. Implement Sci 2011;6:10 [FREE Full text] [doi: 10.1186/1748-5908-6-10] [Medline: 21299860]

3. Dombrowski S, Sniehotta F, Avenell A. Current issues and future directions in Psychology and Health: Towards a cumulative science of behaviour change: Do current conduct and reporting of behavioural interventions fall short of best practice? Psychology \& Health 2007 Dec;22(8):869-874. [doi: 10.1080/08870440701520973]

4. Strecher V. The Internet: Just another smoking cessation tool? Addiction 2008 Mar;103(3):485-486. [doi: 10.1111/j.1360-0443.2008.02144.x]

5. Webb TL, Joseph J, Yardley L, Michie S. Using the internet to promote health behavior change: a systematic review and meta-analysis of the impact of theoretical basis, use of behavior change techniques, and mode of delivery on efficacy. J Med Internet Res 2010;12(1):e4 [FREE Full text] [doi: 10.2196/jmir.1376] [Medline: 20164043]

6. Riley WT, Rivera DE, Atienza AA, Nilsen W, Allison SM, Mermelstein R. Health behavior models in the age of mobile interventions: are our theories up to the task? Transl Behav Med 2011 Mar;1(1):53-71 [FREE Full text] [doi: 10.1007/s13142-011-0021-7] [Medline: 21796270]

7. Safran J, Muran J. Negotiating the Therapeutic Alliance : A Relational Treatment Guide. New York: The Guilford Press; 2003.

8. Wampold B. The great psychotherapy debate: models, methods, and findings. Mahwah, NJ: L. Erlbaum Associates; 2001.

9. Ryan RM, Deci EL. Overview of self-determination theory: An organismic dialectical perspective. In: The Handbook of Self-Determination Research. Rochester: University of Rochester Press; 2002.

10. Marlatt GA, George WH. Relapse prevention: introduction and overview of the model. Br J Addict 1984 Sep;79(3):261-273. [Medline: $\underline{6595020]}$

11. Bickmore TW, Picard RW. Establishing and maintaining long-term human-computer relationships. ACM Trans Comput-Hum Interact 2005 Jun 01;12(2):293-327. [doi: 10.1145/1067860.1067867]

12. Bickmore T, Gruber A, Picard R. Establishing the computer-patient working alliance in automated health behavior change interventions. Patient Educ Couns 2005 Oct;59(1):21-30. [doi: 10.1016/j.pec.2004.09.008] [Medline: 16198215]

13. Barazzone N, Cavanagh K, Richards DA. Computerized cognitive behavioural therapy and the therapeutic alliance: a qualitative enquiry. Br J Clin Psychol 2012 Nov;51(4):396-417. [doi: 10.1111/j.2044-8260.2012.02035.x] [Medline: 23078210]

14. Ormrod JA, Kennedy L, Scott J, Cavanagh K. Computerised cognitive behavioural therapy in an adult mental health service: a pilot study of outcomes and alliance. Cogn Behav Ther 2010;39(3):188-192. [doi: 10.1080/16506071003675614] [Medline: 20485996]

15. Peck DF. The therapist-client relationship, computerized self-help and active therapy ingredients. Clin Psychol Psychother 2010;17(2):147-153. [doi: 10.1002/cpp.669] [Medline: 19946947]

16. Meyer B, Bierbrodt J, Schröder J, Berger T, Beevers C, Weiss M, et al. Effects of an Internet intervention (Deprexis) on severe depression symptoms: Randomized controlled trial. Internet Interventions 2015 Mar;2(1):48-59. [doi: 10.1016/j.invent.2014.12.003]

17. Morris ME, Aguilera A. Mobile, Social, and Wearable Computing and the Evolution of Psychological Practice. Prof Psychol Res Pr 2012 Dec;43(6):622-626 [FREE Full text] [doi: 10.1037/a0029041] [Medline: 25587207]

18. Danaher BG, Brendryen H, Seeley JR, Tyler MS, Woolley T. From black box to toolbox: Outlining device functionality, engagement activities, and the pervasive information architecture of mHealth interventions. Internet Interv 2015 Mar 1;2(1):91-101. [doi: 10.1016/j.invent.2015.01.002] [Medline: 25750862]

19. De Boni M, Richardson A, Hurling R. Humour, Relationship Maintenance and Personality Matching in automated dialogue: A controlled study. Interacting with Computers 2008 May;20(3):342-353. [doi: 10.1016/j.intcom.2007.11.002]

20. Cavanagh K, Millings A. (Inter)personal Computing: The Role of the Therapeutic Relationship in E-mental Health. J Contemp Psychother 2013 Jul 17;43(4):197-206. [doi: 10.1007/s10879-013-9242-z]

21. Brandt CL, Dalum P, Thomsen TT. "I miss the care even though I know it's just a machine": an explorative study of the relationship between an Internet-based smoking cessation intervention and its participants. Health Informatics J 2013 Sep;19(3):233-243. [doi: 10.1177/1460458212470572] [Medline: 23981397]

22. Kaplan B, Farzanfar R, Friedman RH. Personal relationships with an intelligent interactive telephone health behavior advisor system: a multimethod study using surveys and ethnographic interviews. Int J Med Inform 2003 Aug;71(1):33-41. [Medline: $\underline{\text { 12909156] }}$

23. Cahill J, Barkham M, Hardy G, Gilbody S, Richards D, Bower P, et al. A review and critical appraisal of measures of therapist-patient interactions in mental health settings. Health Technol Assess 2008 Jun;12(24):iii, ix-iii, 47 [FREE Full text] [Medline: $\underline{18510875]}$ 
24. Miller WR, Rollnick S. Motivational Interviewing, Third Edition: Helping People Change (Applications of Motivational Interviewing). New York: The Guilford Press; 2012.

25. Lundahl BW, Kunz C, Brownell C, Tollefson D, Burke BL. A Meta-Analysis of Motivational Interviewing: Twenty-Five Years of Empirical Studies. Research on Social Work Practice 2010 Jan 11;20(2):137-160. [doi: 10.1177/1049731509347850]

26. Markland D, Ryan RM, Tobin VJ, Rollnick S. Motivational Interviewing and Self-Determination Theory. Journal of Social and Clinical Psychology 2005 Sep;24(6):811-831. [doi: 10.1521/jscp.2005.24.6.811]

27. Patrick H, Williams GC. Self-determination theory: its application to health behavior and complementarity with motivational interviewing. Int J Behav Nutr Phys Act 2012;9:18 [FREE Full text] [doi: 10.1186/1479-5868-9-18] [Medline: 22385676]

28. Ryan RM, Deci EL. Self-determination theory and the facilitation of intrinsic motivation, social development, and well-being. Am Psychol 2000 Jan;55(1):68-78. [Medline: 11392867]

29. Voogt CV, Poelen EA, Kleinjan M, Lemmers LA, Engels RC. The development of a web-based brief alcohol intervention in reducing heavy drinking among college students: an Intervention Mapping approach. Health Promot Int 2013 Dec;29(4):669-679 [FREE Full text] [doi: 10.1093/heapro/dat016] [Medline: 23525645]

30. Dalum P, Schaalma H, Kok G. The development of an adolescent smoking cessation intervention--an Intervention Mapping approach to planning. Health Educ Res 2012 Feb;27(1):172-181 [FREE Full text] [doi: 10.1093/her/cyr044] [Medline: 21730251]

31. Tensil M, Jonas B, Strüber E. Two fully automated web-based interventions for risky alcohol use: randomized controlled trial. J Med Internet Res 2013;15(6):e110 [FREE Full text] [doi: 10.2196/jmir.2489] [Medline: 23742808]

32. Friederichs SA, Oenema A, Bolman C, Guyaux J, van Keulen H, Lechner L. I Move: systematic development of a web-based computer tailored physical activity intervention, based on motivational interviewing and self-determination theory. BMC Public Health 2014;14:212 [FREE Full text] [doi: 10.1186/1471-2458-14-212] [Medline: 24580802]

33. Moreau M, Gagnon M, Boudreau F. Development of a fully automated, web-based, tailored intervention promoting regular physical activity among insufficiently active adults with type 2 diabetes: integrating the I-change model, self-determination theory, and motivational interviewing components. JMIR Res Protoc 2015;4(1):e25 [FREE Full text] [doi: 10.2196/resprot.4099] [Medline: 25691346]

34. Brendryen H, Kraft P, Schaalma H. Looking Inside the Black Box: Using Intervention Mapping to Describe the Development of the Automated Smoking Cessation Intervention 'Happy Ending'. The Journal of Smoking Cessation 2010 Jun;5(1):29-56. [doi: $10.1375 /$ jsc.5.1.29]

35. Brendryen H, Johansen A, Nesvåg S, Kok G, Duckert F. Constructing a Theory- and Evidence-Based Treatment Rationale for Complex eHealth Interventions: Development of an Online Alcohol Intervention Using an Intervention Mapping Approach. JMIR Res Protoc 2013;2(1):e6 [FREE Full text] [doi: 10.2196/resprot.2371] [Medline: 23612478]

36. Rose GL, Skelly JM, Badger GJ, Naylor MR, Helzer JE. Interactive voice response for relapse prevention following cognitive-behavioral therapy for alcohol use disorders: a pilot study. Psychol Serv 2012 May;9(2):174-184 [FREE Full text] [doi: 10.1037/a0027606] [Medline: 22662731]

37. Elfeddali I, Bolman C, Candel MJ, Wiers RW, de Vries H. Preventing smoking relapse via Web-based computer-tailored feedback: a randomized controlled trial. J Med Internet Res 2012;14(4):e109 [FREE Full text] [doi: 10.2196/jmir.2057] [Medline: 22903145]

38. Bartholomew L, Parcel G, Kok G, Gottlieb N, Fernandez M. Planning Health Promotion Programs: An Intervention Mapping Approach. San Fransisco, CA: Jossey-Bass; 2011.

39. Danaher BG, McKay HG, Seeley JR. The information architecture of behavior change websites. J Med Internet Res 2005;7(2):e12 [FREE Full text] [doi: 10.2196/jmir.7.2.e12] [Medline: 15914459]

40. Sassen B, Kok G, Mesters I, Crutzen R, Cremers A, Vanhees L. A web-based intervention for health professionals and patients to decrease cardiovascular risk attributable to physical inactivity: development process. JMIR Res Protoc 2012;1(2):e21 [FREE Full text] [doi: 10.2196/resprot.1804] [Medline: 23612470]

41. Kok G, Harterink P, Vriens P, Zwart O, Hospers HJ. The gay cruise: Developing a theory- and evidence-based Internet HIV-prevention intervention. Sex Res Soc Policy 2006 Jun;3(2):52-67. [doi: 10.1525/srsp.2006.3.2.52]

42. Jacobs NC, Völlink T, Dehue F, Lechner L. Online Pestkoppenstoppen: systematic and theory-based development of a web-based tailored intervention for adolescent cyberbully victims to combat and prevent cyberbullying. BMC Public Health 2014;14:396 [FREE Full text] [doi: 10.1186/1471-2458-14-396] [Medline: 24758264]

43. Vonk NA, Huirne JA, Pittens CA, van Mechelen WR, Broerse JE, Brölmann HA, et al. eHealth program to empower patients in returning to normal activities and work after gynecological surgery: intervention mapping as a useful method for development. J Med Internet Res 2012;14(5):e124 [FREE Full text] [doi: 10.2196/jmir.1915] [Medline: 23086834]

44. van Genugten L, van Empelen P, Flink I, Oenema A. Systematic development of a self-regulation weight-management intervention for overweight adults. BMC Public Health 2010;10:649 [FREE Full text] [doi: 10.1186/1471-2458-10-649] [Medline: 20979603]

45. Robben SH, Huisjes M, van Achterberg T, Zuidema SU, Olde Rikkert MG, Schers HJ, ZOWEL NN Study Group. Filling the Gaps in a Fragmented Health Care System: Development of the Health and Welfare Information Portal (ZWIP). JMIR Res Protoc 2012;1(2):e10 [FREE Full text] [doi: 10.2196/resprot.1945] [Medline: 23611877] 
46. Heinrich E, Schaper N, de Vries N. Development of the web-based type 2 diabetes education programme: DIEP. European Diabetes Nursing 2009 Sep;6(2):51-56. [doi: 10.1002/edn.135]

47. Drozd F, Haga SM, Brendryen H, Slinning K. An Internet-Based Intervention (Mamma Mia) for Postpartum Depression: Mapping the Development from Theory to Practice. JMIR Res Protoc 2015;4(4):e120 [FREE Full text] [doi: 10.2196/resprot.4858] [Medline: 26476481]

48. Plaete J, De Bourdeaudhuij BI, Verloigne M, Oenema A, Crombez G. A Self-Regulation eHealth Intervention to Increase Healthy Behavior Through General Practice: Protocol and Systematic Development. JMIR Res Protoc 2015;4(4):e141 [FREE Full text] [doi: 10.2196/resprot.4835] [Medline: 26694101]

49. Oosterom-Calo R, Te Velde SJ, Stut W, Brug J. Development of Motivate4Change Using the Intervention Mapping Protocol: An Interactive Technology Physical Activity and Medication Adherence Promotion Program for Hospitalized Heart Failure Patients. JMIR Res Protoc 2015;4(3):e88 [FREE Full text] [doi: 10.2196/resprot.4282] [Medline: 26195072]

50. Geense WW, van Gaal BG, Knoll JL, Cornelissen EA, Schoonhoven L, Kok G. Online Support Program for Parents of Children With a Chronic Kidney Disease Using Intervention Mapping: A Development and Evaluation Protocol. JMIR Res Protoc 2016;5(1):e1 [FREE Full text] [doi: 10.2196/resprot.4837] [Medline: 26764218]

51. Park EW, Tudiver FG, Campbell T. Enhancing partner support to improve smoking cessation. Cochrane Database Syst Rev 2012;7:CD002928. [doi: 10.1002/14651858.CD002928.pub3] [Medline: 22786483]

52. Prescott P, Børtveit T. Helse og atferdsendring. Oslo: Gyldendal akademisk; 2004.

53. Batra A, Collins SE, Torchalla I, Schröter M, Buchkremer G. Multidimensional smoker profiles and their prediction of smoking following a pharmacobehavioral intervention. J Subst Abuse Treat 2008 Jul;35(1):41-52. [doi: 10.1016/j.jsat.2007.08.006] [Medline: 17931825$]$

54. Carver C, Scheier M. On the Self-Regulation of Behavior. Cambridge: Cambridge University Press; 1998.

55. Marlatt GA, Donovan DM, editors. Relapse Prevention: Maintenance Strategies in the Treatment of Addictive Behaviors. 2nd edition. New York: The Guilford Press; 2005.

56. Beck AT, Haigh EA. Advances in cognitive theory and therapy: the generic cognitive model. Annu Rev Clin Psychol 2014;10:1-24. [doi: 10.1146/annurev-clinpsy-032813-153734] [Medline: 24387236]

57. Brendryen H, Kraft P. Happy ending: a randomized controlled trial of a digital multi-media smoking cessation intervention. Addiction 2008 Mar;103(3):478-84; discussion 485. [doi: 10.1111/j.1360-0443.2007.02119.x] [Medline: 18269367]

58. Mori M, MacDorman K, Kageki N. The Uncanny Valley [From the Field]. IEEE Robot Automat Mag 2012 Jun;19(2):98-100. [doi: 10.1109/MRA.2012.2192811]

\section{Abbreviations \\ CMI: computerized motivational interviewing \\ MI: motivational interviewing \\ RCT: randomized controlled trial \\ SMS: short message service}

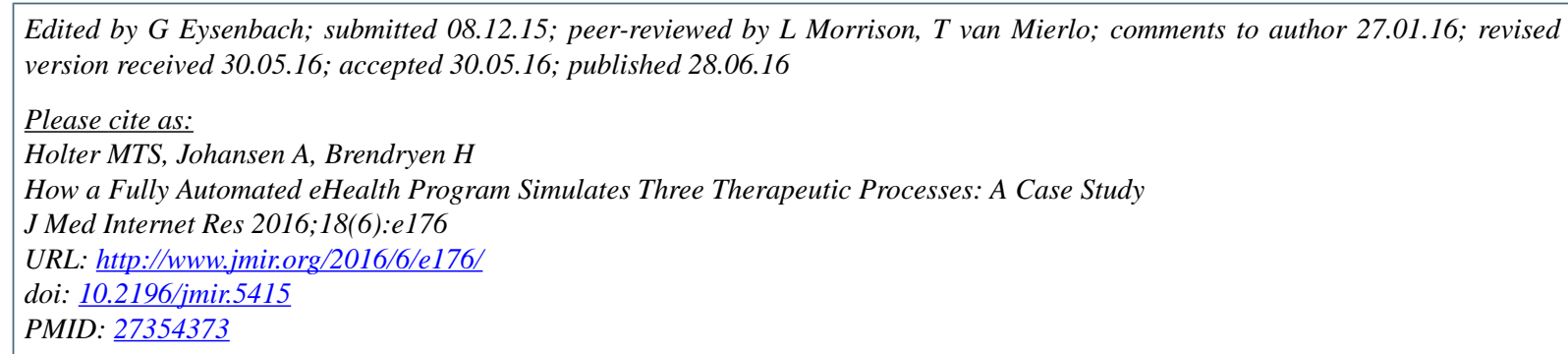

CMarianne T. S. Holter, Ayna Johansen, Håvar Brendryen. Originally published in the Journal of Medical Internet Research (http://www.jmir.org), 28.06.2016. This is an open-access article distributed under the terms of the Creative Commons Attribution License (http://creativecommons.org/licenses/by/2.0/), which permits unrestricted use, distribution, and reproduction in any medium, provided the original work, first published in the Journal of Medical Internet Research, is properly cited. The complete bibliographic information, a link to the original publication on http://www.jmir.org/, as well as this copyright and license information must be included. 